Article

\title{
Between Earth and Sky: Transcendence, Reality, and the Fairy Tale in Pan's Labyrinth
}

\author{
Savannah Blitch \\ Department of English, Arizona State University, P.O. Box 870302 Tempe, AZ 85287-0302, USA; sblitch@asu.edu \\ Academic Editor: Claudia Schwabe \\ Received: 31 March 2016; Accepted: 16 May 2016; Published: 25 May 2016
}

\begin{abstract}
Though it is now a decade since its release, Guillermo del Toro's Pan's Labyrinth (2006) remains a work of filmic art which plays upon our deep-rooted and mercurial relationship with fairy tales and folklore. By turns beautiful and grotesque, Pan's Labyrinth is a complex portrait of the clash between Ofelia's fairy tale world and that of the brutal adults around her. This article will provide an analysis of the juxtaposition of the film's imagery of closed/open circles, their respective realms, and how Ofelia moves between the two. I will argue that these aspects create an unusual relationship between the fairy tale universe and the physical one, characterized by simultaneous displacement and interdependency. Ofelia acts as a mediatrix of these spheres, conforming to neither the imposed rules of her historical reality nor the expected structural rules of fairy tales, and this refusal ultimately allows her transcendence from the circumscribed realm of the liminal into Victor Turner's "liminoid" space, escaping the trap of binarism.
\end{abstract}

Keywords: fairy tales; liminoid; Pan's Labyrinth; Guillermo del Toro; film

\section{Introduction}

Upon the release of Pan's Labyrinth in 2006, the film immediately caught and held international attention. Its premiere at the Cannes Film Festival was swiftly followed by swathes of praise as critics, used to overlooking 'popular' creators, were pleasantly surprised to find that "[ $\mathrm{t}]$ he Mexican is not only a skilled director mining a rich vein in fantasy/horror; he is an artist full stop" [1]. In 2007, the year of its wide release, the movie became a much-announced title in worldwide awards, among its many wins were three Academy Awards, the Mexican Golden Ariel (the highest film award) and eight Silver Ariels, another eight Spanish Goyas, and three British Academey of Film and Television Arts Awards [2]. Guillermo del Toro's labor of love-_"I gave back my entire salary in order to get the film made the way I wanted it." - had clearly struck a ringing chord [3].

By turns hopeful and brutal, fantastical and realistic, gruesome and beautiful, del Toro's story is fixated on the dualities inherent in humanity. In this paper, I will first establish the symbolism of reality versus that of the fairy tale, guided by Curtiss Hoffman's analogy of the line and circle in The Seven Story Tower. Then, by analyzing the juxtaposition of these symbols, their respective realms in the film, and further, how the child protagonist Ofelia moves between the two, I demonstrate that the film creates an unusual relationship between them characterized by simultaneous displacement and interdependency. Ofelia acts as a mediatrix of these spheres, conforming to neither the imposed rules of her historical reality nor the expected, structural rules of fairy tales. This refusal ultimately allows her transcendence from the circumscribed realm of the liminal into Victor Turner's "liminoid" space, thus escaping the trap of binarism.

\section{The Dialectic of Fairy Tale and Reality: Closed and Open Circles}

In the course of this paper, the closed (alternatively referred to as full) circle and the open (alternatively referred to as broken) circle will serve as representative of the real world and the 
world of fairy tales, respectively. The dichotomy of these symbols and their meanings is most easily described with the aid of Curtiss Hoffman, who covers symbolism in mythic narratives extensively in The Seven Story Tower. Although his interpretations of the seven designated "key" myths are not always the most convincing, heavily colored by Freudian readings and a rather mystical take on the Collective Unconsciousness, Hoffman does identify a number of interesting recurrent themes. His most useful ideas appear in the first chapter of the book ([4], pp. 1-21) where he introduces the model of an overarching "dialectic of science and myth" ([4], p. 8) that shapes human cultural practice. He identifies the former as linear and the latter as circular, and assigns the two fields their defining attributes accordingly. Science is "analytic", "progressive", "rational", and "masculine" where myth is "synthetic", "traditional", "transcendent", and "feminine". They act as complementary opposites of each other. While the relationship between the full vs. the broken circle is more subtle, the general principle remains the same. The closed circle describes reality, and, much like Hoffman's linear depiction of science, represents logic and stability. However, as informed by Pan's Labyrinth it additionally symbolizes repetition and masculine tendencies. The motion and fluidity often linked with the full circle is perverted into a locked holding pattern, where movement is only permitted in the sanctioned direction and the structure as a whole is constant and static. The broken circle, on the other hand, signifies emotion, volatility, liminality, and femininity.

In del Toro's characteristically ornate style, the film tells the story of Ofelia, a young, fanciful girl in the Spain of 1944, five years after the bloody Civil War. She is daughter to a sickly, pregnant mother and a wicked stepfather, one of the top-ranking generals of the fascist army. General Vidal moves them to the country to improve his wife's health, anxious for his unborn son. Their new residence shares the forest with an ancient labyrinth, home to an equally ancient faun who reveals that Ofelia is the reincarnation of Princess Moana of the Underworld. He presents her three tasks which she must complete before the moon becomes full if she ever hopes to escape the mortal world and reclaim her birthright [5]. Del Toro is a master of symbolism and subtext, a skill that takes center stage in a film such as Pan's Labyrinth, which is steeped in ambiguity and multiple meanings. However, some clarity can be gleaned from investigating how certain images such as the closed and open circles appear in the narrative, how they impact it, and thus how the overall meaning is affected.

First, the closed circle: it appears most prominently as the full moon, the cycle of reincarnation, and the clock imagery surrounding Captain Vidal. In the first case, initially the importance of the full moon to Ofelia's tasks would seem to align it more closely with the fairy tale world, but in fact the faun very clearly stipulates that she must complete the three trials before the full moon, when its circle is still incomplete. Only up until when the edges meet can she hope to counteract the pull of the second prominent full circle, her own pattern of reincarnation. While this is a fantastical device, its placement within the mortal world and its closed nature establish it as firmly representative of reality. According to the faun, her soul is being recycled between bodies and across centuries; she is stuck in a feedback loop, reinforcing her human existence the same way reality strengthens itself through constant directional movement. The third and most powerful of reality's symbolic strongholds is the imagery of the clock. Vidal's pocket watch accompanies him in almost every scene, and his quarters in the mill are dominated by huge ridged wheels which mimic clock gears. The strictly regimented turning of both very deliberately reinforces the relentless press of reality. Vidal maintains the watch meticulously to ensure its movement, just as he continues (and simultaneously overwrites) his father's legacy. "Time is linked to order, and order to oppression," Jack Zipes notes, and indeed, as the captain is consumed by the flow of time and his place in it, he excels at oppression ([6], p. 238).

The broken circle often appears in close connection to the full circle, notably as Ofelia's birthmark, the labyrinth, and the shattered clock face. Much like Vidal carries his pocket watch, Ofelia carries on her body the perpetually open symbol of the crescent moon, planting her firmly on the side of fairy tales. The structure of the labyrinth itself is an open circle, and intentionally situated right across from the full, turning wheels of the millhouse. The labyrinth's dilapidated condition speaks to one of the shortcomings of the structure of the broken circle, which is that although its openings allow 
for more flexibility and dynamism than the full circle, they are also points of weakness. Without the closed circle's benefit of feeding into itself, the open circle easily becomes brittle in the absence of attention and slips into dormancy. One of the most interesting appearances of the open circle is in Vidal's broken clock face. Overlaid on the strong realist symbol of the clock itself, the shattered circle is vehemently denied by Vidal, though he can never quite escape it. Paul Julian Smith remarks in a review for Film Quarterly that "Captain Vidal ... embodies a masculinity ... so exclusive it barely acknowledges the existence of the feminine," and just as he presumes to greet Ofelia and the pregnant Carmen with the masculine plural because he refuses to accept anything but a son, he refuses to allow the broken circle any foothold of emotion or feminizing influence by facing its presence ([7], p. 6).

\section{A Series of Interlockings: the Dance of the Two Realms}

As these worlds edge closer together throughout the film, Ofelia slowly bridging the gap between them, it becomes increasingly apparent that their interactions toe a delicate line between coexistence and separation. Tracie Lukasiewicz classifies this balance as "neomagical realism", which she uses in the sense of having neither a "conventional fairy tale's acceptance of magic within its fantasy world" nor "magical realism's incorporation of magic into the real world" ([8], pp. 61-62). Continuing my analogy of the closed and open circles, their relationship is what can best be described as a series of interlockings in which the mouth of the open circle hooks around the edge of its unbroken counterpart and for certain moments occupies not exactly the same space but nearly so, closely enough that their movements affect each other. From the moment that Ofelia makes contact with the fairy in the forest, the realms begin to converge upon and affect each other. Her initial meeting with the faun and the first task takes place deep in the labyrinth and the forest, completely immersed in the fairy world, and the object of power she receives, a magic book, allows her to access the fantastic while maintaining distance. Afterwards, the situation escalates as the faun appears in the midst of the real world, in her bedroom, and presents her with a talisman to further link them together: the mandrake root. Unlike the passive book, this object requires blood sacrifice that creates a concrete bond, the strength of which is demonstrated as Carmen throws the creature into the fire and immediately doubles over in agony, forfeiting the health it provides. The second task occurs at an even lower degree of separation, beginning and ending right in Ofelia's room. It cannot be chance, either, that the night that Ofelia is sent to bed without dinner in the real world, she is confronted with a supernatural feast in the other; at this point they are too closely linked for coincidence. Smith describes it thus: though the "plot is placed quite precisely in a historical moment ... the material effects of that desperate moment ... are juxtaposed with, are indeed inextricable from, the fantastic realms" ([4], p. 5). On the night of the final battle, when the realms are at their closest, Ofelia travels into the labyrinth and achieves immortality at its center, while in a direct inversion Vidal walks out of it and at its gate is condemned to death and, worse, obscurity.

Still, though the fantasy world deeply impacts Vidal, the film clearly illustrates the limited scope of the two worlds' connection when he confronts his stepdaughter in the labyrinth and, through a moment of changed camera perspective, there is only empty air where Ofelia sees the faun. At this instant, what has been suggested throughout the film-as when Mercedes, the housekeeper who becomes close to Ofelia, admits that she does not believe in magic anymore, or when a distraught Carmen insists, "Magic does not exist. Not for you, me, or anyone else." - becomes cemented: Ofelia is the only one who possesses what Zipes calls "real double vision, unique powers that enable her to see two worlds at the same time" ([6], p. 237). By the nature of their interlocking, these worlds can coincide temporally and thematically without actually touching or otherwise mixing. As Lukasiewicz comments, "[t]here is no incorporation of one space into another, nor is there a point when they completely converge" ([8], p. 66). Del Toro constructs a universe where the worlds do not need to be melded in order to affect each other, and more importantly, where it becomes a conscious choice to cross into or even acknowledge the fairy tale realm. Among the cast of disillusioned adults, Ofelia is a 
unique figure: she makes the choice to believe, and it is this faith that allows her to stand on the rim of the full circle, look across the void, and see the rings of the open circle hovering beyond.

\section{4. "One Can Only Get Lost in a Maze": The Symbolic Significance of the Labyrinth}

The common questions of whether Ofelia's fantastic journey actually happened lose their urgency in this light. If the worlds were completely incorporated, there would be no reason to doubt the validity of our sojourns into Ofelia's "double vision"; if the worlds were never shown to overlap, then the easiest assumption would be that the events were nothing but fabrication. As it is, the tenuous almost-blurring of the boundaries fails to make a solid impression one way or another. While this ambiguity might be frustrating in other genres, in the case of the fairy tale film-and especially considering the reality-fantasy relationship established in Pan's Labyrinth-it is completely natural. The fantastic thrives upon in-betweens and suspension of disbelief. To fixate then on what "really" happened distracts from the actual focus of the narrative, which has little to do with any binary-driven interpretation of reality. Del Toro's film is driven by the becoming of its two main characters, Ofelia and Mercedes, which means that what is of most interest to the story is that they end beyond where they began, not necessarily where that point specifically is. What matters is the change, and that the audience experiences it with them, and it is for this reason that the labyrinth is so central to the film.

The Dictionary of Literary Symbols notes as an afterthought in its entry on labyrinths that "[t]here is a technical distinction between a labyrinth and a maze, the labyrinth being "unicursal" (with one path), and the maze "multicursal" (with branching paths)," meaning that "one can only get lost in a maze" ([9], p. 107). Accordingly, the movie—rather than presenting winding alternate routes and possibilities-follows a singular spiral path, one that may curve in on itself and challenge perceptions, but ultimately remains steady. Del Toro himself confirms the sentiment in an interview, commenting that "A maze is a place where you get lost, but a labyrinth is essentially ... an ethical, moral transit to one inevitable center" [6]. Ofelia, by the end of the movie, has fully realized herself along the course of this transit, which positions her in a unique place to jump ship, as it were, into the waiting folds of the open-circle world of faerie. Characteristic of the non-linear, fantastical realm, this truth is actually given away within the opening minutes of the movie, the very first time we see Ofelia: she lies on the ground, breathing shallowly, the plaintive lullaby humming over her, and the blood on her face runs backwards into her nose. "The first scene reveals that she is alive after her death," Zipes notes, "and the rest of film ... explain[s] why her blood returns to her and fills her with life" ([6], p. 238). Even this commentary, however, I feel places undue emphasis on categorizing her as alternatively "alive" or "dead", when the point is that she made it out of the sphere of restriction and dichotomies.

\section{Memory and Forgetting: The Influence of the Spanish Civil War and its After-Effects}

This is an especially remarkable achievement given that the movie takes place in a historical setting which was defined by those very two things. Ofelia is the child of a country which has just suffered the agony of a nation-wide ideological divide and continues to be plagued by the mentality of 'us versus them', as the conflict between the resistance fighters and Vidal's forces demonstrates. The northern Spain in Pan's Labyrinth is still a fictional version, however, and it is more shaped by the after-effects rather than the actual events of the time period in which it is supposed to take place. One of the strongest influences is the tension between the Pact of Forgetting and the Law of Historical Memory, as the debate leading up to the eventual passing of the latter was contemporary to the filming ([10], p. 26). Their vague, grand titles almost sound like they belong to fairy tales themselves, which perhaps communicates how profoundly the Civil War transformed Spanish identity. The first was not an official law but an informal agreement put in place shortly after Franco's death in 1973. Under the Pact, political scientist Omar Encarnación describes how

the conflict came to be understood as a guerra de locos (war of collective madness) that produced no winners and losers, only victims. In this problematic formulation, both sides bore equal responsibility for the Civil War, which made it redundant to ascribe blame to 
any particular group in society. The important thing was to ensure that a similar conflict would never happen again, and the best way to achieve that result was to forget and look to the future ([11], pp. 28-29).

The 2007 Law of Historical Memory overturned this through an unequivocal condemnation of fascism and a number of policies intended to heal and reverse the damage of the Franco dictatorship, such as increased pensions for veterans, reparation payments, and, significantly, a set of injunctions for "the exhumation and reburial of unmarked Civil War graves" ([11], p. 166). These opposing policies not only represent changing forms of government but radically different perceptions of time as well. The Pact of Forgetting, although intended to smooth the state's transition into democracy, is characteristically fascist in tone, articulating the same single-minded focus on progress that motivates Captain Vidal. Thus, Ofelia implicitly becomes aligned with the redemptive Law of Historical Memory, which moves forward by turning to the past and redeems the living by bringing the dead back to the surface.

\section{A Search for the Lost Self: Fairy Tale Tropes Re-imagined and Re-purposed by Ofelia}

In a way, the Pact of Forgetting embodied the same sort of erasure inherent in the typical "and they lived happily ever after"; fairy tales often act as vehicles for the reinforcement of such cultural constructs. Characters enter and traverse a liminal space and come out the other end confirming or having learned those values. For example, Cinderella's ability to move between her identities and the social strata lasts only three nights, and the youngest daughter in "East of the Sun and West of the Moon" eventually leaves the magical land to settle into life with her now-permanently-human husband. Pan's Labyrinth incorporates several fairy tale tropes and narratives, but because Ofelia is the center of them, she de-stabilizes their traditional structure and undermines their sanctioned subtextual messages. Her general narrative fits neatly into the Aarne-Thompson-Uther tale type 425A, The Search for the Lost Husband: it begins with an enchanted bargain which goes wrong, followed by tasks of mounting difficulty and the helpers which aid her advancement [12]. The vital divergence is that rather than chasing after a vanished husband, Ofelia is laboring towards the recovery of her former self. The union at the end of the film is entirely internal and individual, and thus deeply subversive of the original type, which revolves around the repentance of the disobedient wife, demonstrating herself to be worthy of the union with her prince. The associated tasks reflect this by focusing on domestic skills, such as the washing of the shirt in "East of the Sun and West of the Moon" [13]. Ofelia's trials are not nearly so gender role-specific, and have her slaying monsters and traveling into the underworld; since her quest is to prove her worth to herself, her trials are about physical and moral courage, the things which are important to her, not a husband or society. She is that rare protagonist that possesses acute knowledge of the genre she inhabits, and when her "real" life intrudes (such as with the birth of her brother and death of her mother) she questions the rules and morality which govern that genre. Pan's Labyrinth becomes a film about a girl who amalgamates a new fairy tale out of those given to her; rather than conforming herself to their often strict rules, she creates her own narrative.

\section{A World of Her Devising: The Liminoid in Pan's Labyrinth}

In "A Review of 'Ethnopoetics'," Victor Turner introduces his conception of the liminoid, a state of being tangential to the liminal but "more flexible and multifarious than the liminal, which is bounded more firmly by ritual constraints ... It is a world of as if, may be, might have been, sometimes should be" ([14], p. 341). It is a land of uncertainty and possibility, without the cultural demand to pass through and continue on. "Liminal phenomena" such as rites of passage are, he says, "integrated into the total social process," because they follow a script which must be seen through to its completion ([14], p. 85). On the other hand, "liminoid phenomena" spring up outside of the social system, in the realm of the experimental ([14], pp. 85-86). The liminoid is the liminal, uncaged, its mysteries kept unto itself and not submitted to maintenance of the societal structure. 
Ofelia, in her Icarian escape from the labyrinth and the narrative, elects to be part of the undefined, liminoid territory. She takes her identity into her own hands instead of allowing society to stipulate when, where, and how she should make the many societal and cultural transitions expected of her. The most basic of these is her prematurely induced movement from childhood to adulthood, which in turn is triggered by the intrusion of the fascist, modernized present on the rural, mythic past. This latter frictive encounter is symbolized by the presence of the mill in the forest. Ofelia, though not the only character to move between the two, is the only one shown equally in both environments because of her liminal existence. However, rather than choose either one she instead moves outside the traditional dichotomy into the liminoid, where she is both ancient and ageless, the distant past and infinite present, a story and a real presence. Either/or does not exist in the intermingled space where the closed circle meets the open one. Her intimate connection with the world of fairy tales allows her to transcend such definitive labeling and binary thought, rising above all of the adult figures who abused or talked down to her, in a way that Smith proposes "perhaps [suggests] ... that fantasy is somehow proportionate to or compensatory for the horrors of the real" ([7], p. 8). The small, delicate flower that del Toro chooses to close the film on seems a woefully inadequate reparation compared to the graphic and self-satisfied violence portrayed in the rest of the movie, but the possibility of the blossom, like the fairy tale world it springs from, is much bigger than itself. It opens to the sunlight the way the open circle turns towards the full one, less constant and more breakable than its counterpart but ready to receive whatever the other has to offer and return it better than it was given.

In the same interview where del Toro acknowledges the distinction between mazes and labyrinths, he also makes an equally important and infinitely more moving remark, that "Pan's Labyrinth is a movie about a girl who gives birth to herself into the world she believes in" [3]. Robbed of her father, her home, her mother, and finally her mortal life, the one thing Ofelia refuses to have taken from her is her childhood and the impenetrable faith that comes with it. At the close of the film, standing her ground in the center of her chosen world, Ofelia not only defends her brother but her own innocence and her right to keep something sacred to herself, outside of destructive binaries. She is a labyrinth-pure of direction and purpose-where the others are mazes, and having walked both the closed and open paths, combined she becomes better than them both, like her symbol the flower, with her feet in the earth but her face to the sky.

Conflicts of Interest: The author declares no conflict of interest.

\section{References}

1. José Arroyo. "Pan's Labyrinth." Sight E Sound 16 (2006): 66-68.

2. "Pan's Labyrinth: Awards." IMDb. Available online: http://www.imdb.com/title/tt0457430/awards (accessed on 12 May 2016).

3. BFI Film Forever. "Girl Interrupted." Available online: http://old.bfi.org.uk/sightandsound/feature/49337 (accessed on 12 May 2016).

4. Curtiss Hoffman. The Seven Story Tower. Cambridge: Perseus Publishing, 1999.

5. Pan's Labyrinth. Directed by Guillermo del Toro. New York: Picturehouse, 2006.

6. Jack Zipes. "Pan's Labyrinth.” Journal of American Folklore 121 (2008): 236-40.

7. Paul Julian Smith. "Pan's Labyrinth (El Laberinto Del Fauno)." Film Quarterly 60 (2007): 4-9. [CrossRef]

8. Tracie D. Lukasiewicz. “The Parellelism of the Fantastic and the Real: Guillermo Del Toro's Pan's Labyrinth/El Laberinto Del Fauno and Neomagical Realism." In Fairy Tale Films: Visions of Ambiguity. Edited by Pauline Greenhill and Sidney Eve Matrix. Logan: Utah State University Press, 2010, pp. 60-78.

9. Michael Ferber. A Dictionary of Literary Symbols, 2nd ed. New York: Cambridge University Press, 1999 , p. 231.

10. Mar Diestro-Dópido. Pan's Labyrinth. London: Palgrave Macmillan, 2013.

11. Omar Guillermo Encarnación. Democracy without Justice in Spain: The Politics of Forgetting, 1st ed. Philadelphia: University of Pennsylvania Press, 2014. 
12. Antti Aarne, Stith Thompson, and Hans-Jörg Uther. "Aarne-Thompson-Uther Classification of Folk Tales." Multilingual Folk Tale Database. Available online: http:/ /www.mftd.org/index.php?action=atu (accessed on 10 February 2016).

13. Peter Christen Asbjørnsen, and Jørgen Moe. "East $\mathrm{O}^{\prime}$ the Sun and West $\mathrm{O}$ ' the Moon." Multilingual Folk Tale Database. Available online: http:/ / www.mftd.org/index.php?action=story\&act=select\&id=3246 (accessed on 10 February 2016).

14. Victor Turner. "A Review of 'Ethnopoetics'." In Symposium of the Whole: A Range of Discourse toward an Ethnopoetics. Edited by Jerome Rothenberg and Diane Rothenberg. Berkeley: University of California Press, 1983.

(C) 2016 by the author; licensee MDPI, Basel, Switzerland. This article is an open access article distributed under the terms and conditions of the Creative Commons Attribution (CC-BY) license (http://creativecommons.org/licenses/by/4.0/). 